\title{
Harnessing social capital for maize seed diffusion in Timor-Leste
}

\author{
Modesto Lopes • Harry Nesbitt • Luc Spyckerelle • \\ Natasha Pauli • Julian Clifton • William Erskine
}

Accepted: 23 January 2015 / Published online: 27 February 2015

(C) INRA and Springer-Verlag France 2015

\begin{abstract}
Collective action through farmer groups has contributed widely to improved rural welfare through more effective utilization of resources such as labour, knowledge and influence. The identification of characteristics of farmer groups that are successful today helps develop tomorrow's effective groups. This case study examines characteristics associated with the success of community seed production groups in multiplying and disseminating high-yielding maize seed in Timor-Leste. Previous research from Timor-Leste indicates that the likelihood of an individual adopting a new variety is strongly related to the closeness of social relationships with growers already using that variety. This research explored the hypothesis that social capital, that is social relationships within a farmer group, can be leveraged for development through seed production groups. The groups were established in 2011 for seed production as part of the National Seed System for Released Varieties primarily through previously existing farmer groups. After 2 years, in 2013, a survey was conducted on 30 seed production groups. Successful
\end{abstract}

\footnotetext{
H. Nesbitt • W. Erskine $(\bowtie)$

Centre for Plant Genetics and Breeding (PGB), School of Plant

Biology, The University of Western Australia, 35 Stirling Highway,

Crawley, WA 6009, Australia

e-mail: william.erskine@uwa.edu.au

M. Lopes

Ministry of Agriculture and Fisheries, Comoro, Dili, Timor-Leste

M. Lopes $\cdot$ H. Nesbitt $\cdot$ L. Spyckerelle

Seeds of Life, PO Box 221, Dili, Timor-Leste

N. Pauli $\cdot$ J. Clifton

School of Earth and Environment, The University of Western

Australia, 35 Stirling Highway, Crawley, WA 6009, Australia

W. Erskine

Institute of Agriculture, The University of Western Australia, 35

Stirling Highway, Crawley, WA 6009, Australia
}

groups produced sufficient seed for multiplication at a larger scale the following year, as well as surplus seed for distribution to group members or for sale. Several characteristics were correlated with the quantity of shared seed distributed to individual group members, as a measure of group effectiveness: meeting frequency, with $r$ of 0.69 ; the number of positive leadership traits, with $r$ of 0.57 ; the level of group trust, with $r$ of 0.51 ; and the number of defined management roles within the group, with $r$ of 0.41 . These traits all reflect the strength of social capital and group governance. We conclude that development can be furthered through positively aligning and leveraging existing social capital among farmers for technology dissemination.

Keywords Community seed production · Group characteristics $\cdot$ Multiplication · Dissemination - Agriculture Timor-Leste

\section{Introduction}

Collective action through farmer groups has contributed widely to improved rural welfare. This is especially the case where poor farmers wish to improve access to service delivery, new technologies, input supply chains and markets (Thompson et al. 2009). Farmer organizations assist individuals to compete with large farmers and agri-business (Markelova et al. 2009). Their ability to collectively make decisions about the use of resources such as labour and knowledge can make a difference in the way that they address their shared needs. Collective action may also lead to an improvement in advocacy and policy engagement (Vargas and Burgoa 2007).

The formation of community seed production groups is one form of collective action which can improve farmers' access 
to high-quality planting material. Farmers working in groups can pool resources and adopt new technologies more easily than single farmers who may not have access to the promoted technologies individually. Groups with clear definition of responsibilities for planning and implementation are likely to successfully reach their objectives. In addition, they also work together with government and other related agencies to achieve common goals through action and learning (Gianatti and Llewellyn 2003), and because they form a group, they become more eligible for government or donor support. To explore the understanding of successful seed production groups in developing countries, this paper focuses on a case study of maize seed producers in Timor-Leste.

In developing countries, the identification of high-yielding varieties is a time-consuming process and the multiplication of seed sufficient for distribution to farmers is expensive, with distribution particularly difficult in isolated rural areas. In such regions, there is potential for collective farmer action to promote timely access to seed at affordable prices (Tiwari et al. 2009). The seed industry is poorly developed in Timor-Leste, and the formation of seed production groups is one way to improve access to newly identified improved seed, multiply the seed and sell or trade any surplus.

Crop yields are extremely low in Timor-Leste. For example, national maize (Zea mays L.) yields average approximately $2 \mathrm{t} / \mathrm{ha}$ compared with $4 \mathrm{t} / \mathrm{ha}$ in other South-East Asian countries - Cambodia, Indonesia, Laos, Thailand and Vietnam (Lopes and Nesbitt 2012). Closing this yield gap is a challenge. A long-running research and development program within the Timor-Leste Ministry of Agriculture and Fisheries released high-yielding varieties of the key food crops of maize, rice, sweet potato, cassava and peanuts in 2007 and 2009. The mean yield of a new maize variety (Sele) ranged from 36 to $54 \%$ over local varieties (Williams et al. 2012). Nonetheless, improving access to the new seed has been a slow process using the formal government seed distribution system. The government through one of its development programs started to multiply high-yielding seed for distribution to farmers from 2011 through the cooperation of seed production groups (Seeds of Life 2012b) (Figs. 1 and 2).

The Ministry of Agriculture and Fisheries considers that facilitating the formation of seed production groups in Timor-Leste encourages widespread farming community empowerment and an engagement in seed production. Wellorganized groups are able to not only produce their own seed, but also safely store and distribute the seed within the community. This seed is considered to be "community seed" which is not for commercial use despite being of high quality. Seed production groups are part of a developing country's national seed system for released varieties (Setimela et al. 2004).

The formation of groups with the capacity to successfully multiply and distribute high-quality seed is challenging. There

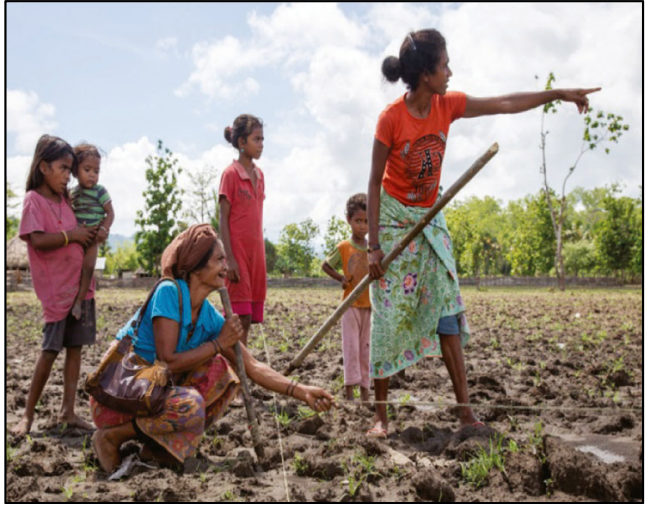

Fig. 1 A women's group in Cailacu working together during the planting season. Picture by Alexia Skok (SoL)

is no information available that identifies the characteristics of successful seed production groups. Understanding how seed production groups function and what characteristics are common to successful groups is crucial to develop an effective strategy for technology dissemination in the farming community. The research described in this study was designed to identify characteristics associated with successful seed production groups which will provide proxy indicators to guide the formation of new groups. Successful group selection can contribute to the development of rural communities in TimorLeste, as well as other developing countries, and help to improve national food security.

Group success may be defined in different ways. Achieving success depends on the objectives and aims of individual groups. The research described here defines successful seed production groups as those that are able to produce sufficient seed for group members and also have some in reserve for emergencies. Studies in Africa found groups that interacted effectively possessed a high level of trust, thereby promoting group cohesion (Place et al. 2004). Successful groups may also possess an efficient decision-making process, effectively manage their activities, be of suitable group size, have a clear group structure, have been formed for the correct reasons, meet frequently, have suitable education and experience,

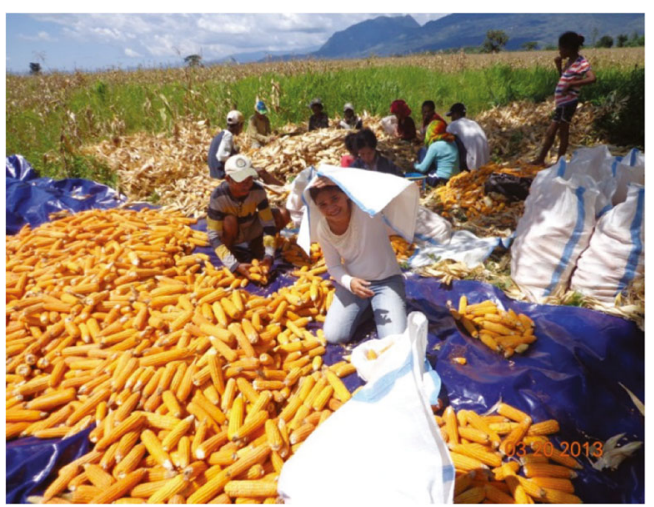

Fig. 2 Seed selection just after harvest in Ritabou. Picture by Dorilanda Lopes, District Seed Officer 
possess an appropriate gender composition and have good extension support (Anandajayasekeram et al. 2008; Sanginga et al. 2001; Bartham and Chitemi 2009). Effective group action depends on how individual members joined the group and their perception of the activities being undertaken (Anandajayasekeram et al. 2008). This study explored the hypothesis that social capital (social relationships in a farmer group) and other characteristics can be leveraged for development through seed production groups in Timor-Leste.

\section{Materials and methods}

\subsection{Sampling}

A representative sample of 30 seed production groups was included in this study. Forty groups in each of seven districts - a total of 280 groups - were supported by the Ministry of Agriculture and Fisheries with a seed production program in 2011-2012. Most of these groups are well organized and were previously involved in collective action prior to becoming seed production groups. These included saving and loan activities and agriculture cooperatives. Group selection was based on a list of 79 primarily pre-existing maize groups in five districts. Selection was stratified within five of the seven districts where the program was operating, with data from the 2011 to 2012 wet season. Six groups were randomly selected from each district, as were the three group members in each group interviewed during the survey. Typically, membership of a seed production group is restricted to neighbouring villages and fields. A total of 90 respondents were interviewed in 2013 to collect yield data from wet seasons 2011 to 2012 and
2012 to 2013 and other information on the group. All groups were multiplying a Ministry of Agriculture and Fisheriesreleased high-yielding maize variety named Sele, as these groups have a common interest to multiply and use improved maize seed. Farmers were located in the districts of Aileu, Ainaro, Bobonaro, Liquiça and Manufahi (Fig. 3). These districts cover a cross section of agro-ecological zones ranging from low altitude, single wet season to higher rainfall sites with a bimodal rainfall pattern.

The focus crop was maize, as it is the most important staple food in Timor-Leste and is cultivated by $83 \%$ of farmers (Seeds of Life 2012a). As maize is cross-pollinating, seed production areas need to be isolated from other varieties to obtain genetically pure high-quality seed, thereby making the success of group multiplication crucial.

\subsection{Data collection}

\subsubsection{Questionnaire design}

A questionnaire was designed for data collection in 2013 from seed production group farmers concerning their wet season results of 2012-2013. Questions covered the demographic characteristics of each respondent, i.e. age, education, gender and the position of the interviewee within the group, as well as group formation and objectives of both the individual and the group. Further questions highlighted governance and support network characteristics, such as decision-making processes, leadership, trust between and among members, extension support and any support from other organizations which describe group characteristics and their potential for being successful. Yield data from the 2011 to 2012 wet season was also

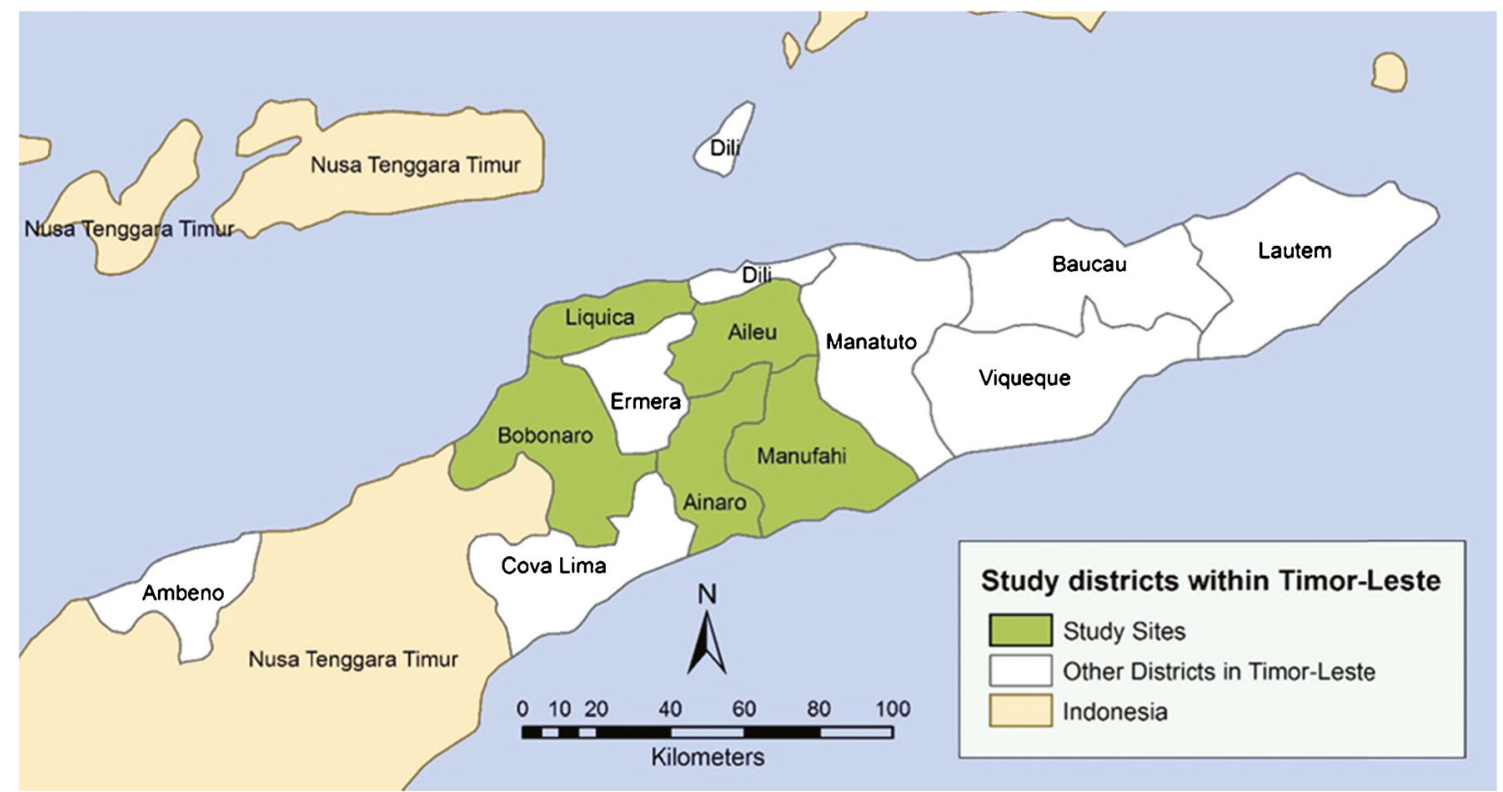

Fig. 3 Map of Timor-Leste showing the five study districts 
collected. As the final question, respondents were asked for their opinion on the direction and future of seed production programs.

\subsubsection{Interviews}

The interview was semi-structured to obtain the maximum amount of relevant information from respondents in one sitting. It followed the interview guidelines of Hay (2005) to focus the questionnaire on issues answering the research questions and utilized ordered but flexible questioning (Hay 2005). Most interviews were conducted in the respondent's house to avoid answers being influenced by other group members including the group leader.

An initial visit was made to the village to arrange an interview time with respondents through collaboration with local extension officers working in the village. On the interview day, the farmer was made comfortable by offering him/her cigarettes and betel nut as is the custom in Timor-Leste when visiting rural households. At this stage, the interviewer provided an introduction to the aims of the study and requested permission to interview. On approval by the farmer, the interview commenced. It took $30-45 \mathrm{~min}$ to complete the interview.

\subsection{Data analysis}

In order to identify characteristics common to successful seed production groups in multiplication and dissemination of high-yielding maize seed, correlation with the amount of seed received by individual group members was used to identify characteristics associated with successful groups. The factors included in the Pearson correlation analysis were as follows:

1. The number of years that the group had worked together, as a measure of the level of experience of the group;

2. The age of the group leader;

3. Gender balance within the group;

4. The level of formal education of group members, assessed as the percentage of group members who had attended school;

5. The number of positive attributes for group structure, defined as the number of the following roles filled in each group: leader, secretary, treasurer and a special coordinator of specific tasks assigned by the group, i.e. seed records and social work;

6. The number of visits by the local extension officer during the cropping season;

7. The group size;

8. The number of positive attributes for group trust, defined as the existence of the following relationships: trust between group members, trust between members and group leader and trust between group members and the community; and

9. The number of positive attributes for members' perceived quality of the group leader from the following criteria: conducting meetings regularly, transparent, efficient in decision-making process and creative.

\section{Results and discussion}

The success of a seed production group was measured by its success in distributing surplus seed to its group members, who then sow the seed either for grain or seed. Apart from this seed disseminated among group members, seed from the group harvest was also set aside for sowing the group's next production cycle, and in some cases, seed was gifted or sold outside the group. The essential purpose of seed production groups was to produce seed to meet members' need as well as-for those groups that had excess seed-disseminating highyielding maize variety seed within the community through their social networks (family, neighbours, other relatives). Diffusion of seed is mostly through informal systems, i.e. gifting, bartering and exchange, which is done by both literate and illiterate farmers

The seed distributed to group members was a measure of success not a measure of the yield achieved in each agroecosystem or district. Each district has its own specific geographical and climatic environment which determines the amount of seed that can be produced by seed production groups. On average, the highest yields in the second year were from the districts Manufahi (1.60 t/ha) and Aileu (1.09 t/ha) followed by Liquiça, Ainaro and Bobonaro (Table 1). By contrast, seed distribution among group members was highest in Aileu and Ainaro followed by Manufahi, Bobonaro and Liquiça, indicating the lack of a close relationship (or weak relationship) between seed distribution among group members and district maize yield.

\subsection{Demographic characteristics}

The groups in the study area possessed between 5 and 25 members with an average of 13 members. Most groups (25 of the 30 interviewed groups) were within the 5-15-member

Table 1 Average yield in the 2012-2013 season compared with the mean quantity of seed shared among group members by district

\begin{tabular}{|c|c|c|c|c|c|}
\hline District & Aileu & Ainaro & Bobonaro & Liquiça & Manufahi \\
\hline Average yield (t/ha) & 1.09 & 0.85 & 0.85 & 1.00 & 1.60 \\
\hline $\begin{array}{l}\text { Mean shared seed }(\mathrm{kg} / \\
\text { group member) }\end{array}$ & 4.7 & 3.2 & 2.0 & 2.0 & 3.0 \\
\hline
\end{tabular}


size. None of the groups had less than five members, and only five groups had more than 16 members. The correlation analysis indicated that group size was not significantly correlated with the amount of seed received by individual group members. While larger groups produced more seed, distribution among a wider audience resulted in each member receiving a similar amount to smaller groups. Large- or small-sized groups did not perform as well as medium-sized groups of ten to 15 members.

\subsubsection{Gender}

Women comprised approximately $52 \%$ of overall group membership. There were a disproportionate number of women in the smaller groups than men, because two of the groups in the five- to ten-member size were women only. Forty-three percent of groups were relatively evenly balanced between men and women. Gender balance within the group was not correlated significantly to the amount of seed received by individual group members (Fig. 4). This result is contrary to that of Sanginga et al. (2001), who maintain that gender balance is a particularly important component in the establishment of effective mechanisms for resource poor farmers. For example, women account for $43 \%$ of the global agriculture labour force (Team and Doss 2011) and it is well documented that women farmers have a greater ability for seed selection and maintenance than men (Lewis and Mulvany 1997). The ability of women in seed production includes seed selection, planting and storage, whereas men have more responsibility in land preparation, fencing, weeding and harvesting. In TimorLeste, women tend to be more skilled at seed selection, planting and storage activities, whilst men tend to do the heavier tasks such as land preparation, carting and carrying (Seeds of Life 2012b). This indicated that gender balance was not an issue in seed production activities as long as groups were of mixed gender. However, different cultures and environments across countries may have different tasks divided between men and women. Participants were aged from 17 to 70 years
Fig. 4 Heat diagram of correlation coefficients between all pairs of group characteristics and the quantity of shared seed. The correlation coefficient at $P<0.01$ is $r=0.46(d f=28)$

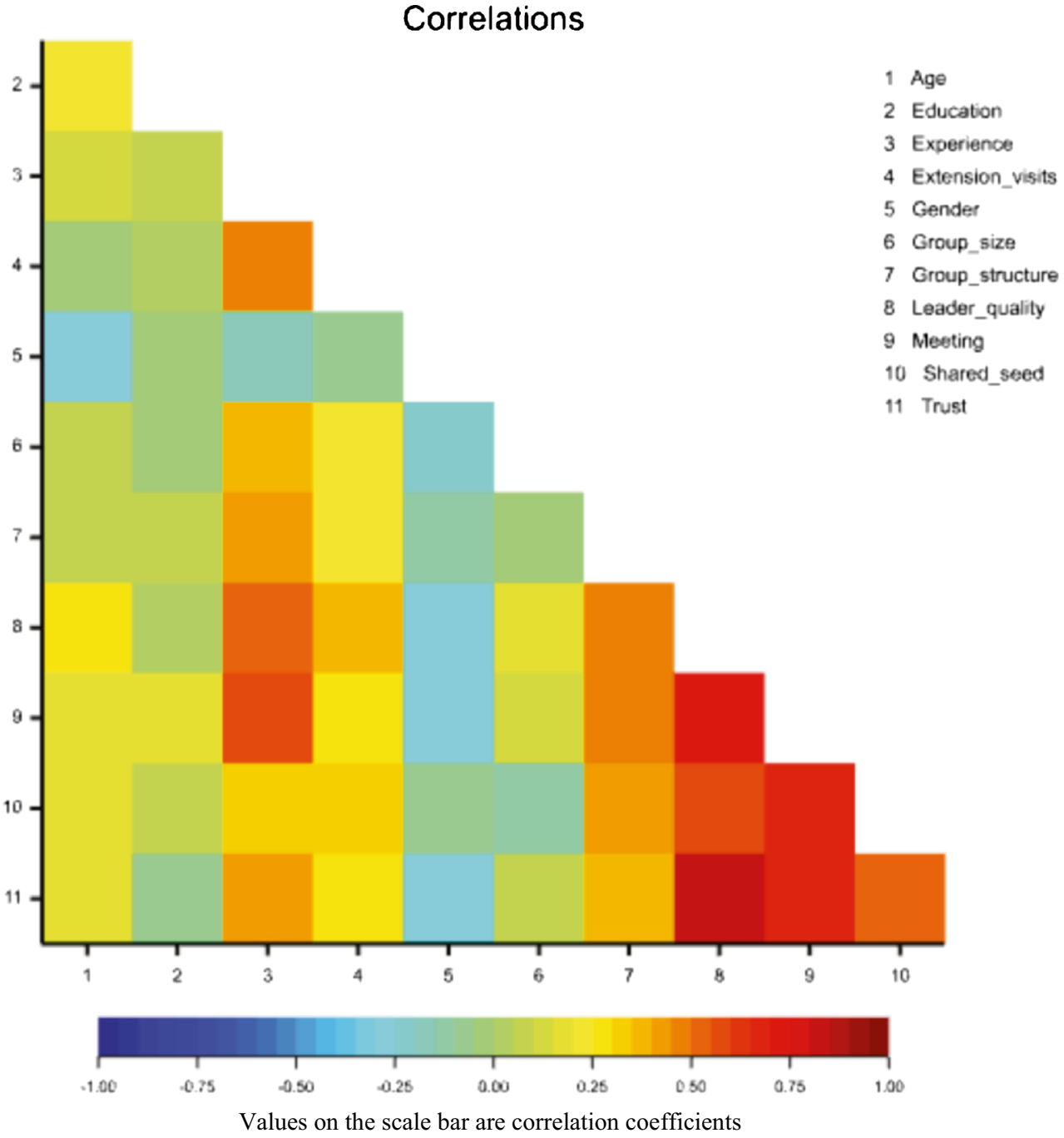


of age with an average of 42 years, and two thirds of group leaders were in the range of 41-60 years of age.

\subsubsection{Group experience, management and decision-making}

All surveyed seed production groups were established in 2011. However, some members were in organized farmer groups before the seed production program was implemented. Seventy percent of the surveyed seed production groups had three or more years of experience operating as groups. Thirteen percent of the groups commenced their activities in 2012 and had a single year of experience. Those groups relying on decision-making from the outside were initially established through information obtained from village extension officers and/or the village chief rather than by their own initiative and were less successful in seed multiplication. From this result, it can be concluded that groups existing prior to receiving support from the Ministry of Agriculture and Fisheries and the Seeds of Life program were cohesive and achieved more group goals than those formed by the village chief. Activity management within seed production groups, on the other hand, was more by collective action rather than individual action; they work together during each activity. Eighty percent of the surveyed groups performed activities collectively. Surprisingly, the amount of experience that the group had was not correlated with the amount of seed received by individual group members. Other characteristics uncorrelated with the amount of seed received by individual group members included age of the leader, gender balance, percentage of group who had received formal education, group size and the number of visits by extension personnel (Fig. 4).

\subsubsection{Education}

Group members had a range of educational levels. Thirty-two percent had no schooling and were illiterate, while one person was educated to diploma level. Most farmers had received some education either at primary school, junior school or high school. The group leaders were slightly better educated than the overall group, although most of them were educated to junior school or lower. Interestingly, education was not correlated with the amount of seed received by individual group members. This conclusion is contrary to that of Bartham and Chitemi (2009) who found that in Tanzania, farmer groups with more years of schooling performed better overall compared to those with little or no schooling. The latter correlation may have been due to the type of collective action; successful farmer groups in Tanzania were involved in marketing, which requires numerous mathematical calculations. Seed production, on the other hand, is more associated with farming experience and group participation. The essential purpose of seed production groups was to produce seed to meet members' need as well as-for those groups that had excess seed - disseminating high-yielding maize variety seed within the community through their social networks (family, neighbours, other relatives). Diffusion of seed is mostly through informal systems, i.e. gifting, bartering and exchange, which is done by both literate and illiterate rural farmers.

\subsection{Governance}

Most interviewed farmers envisaged that joining or forming a seed production group would result in improved seed security. They considered that good seed of the released high-yielding varieties would result in improved yields and that this would lead to greater food security. The amount of seed received by individual group members was considered a measure of success. As shown in Fig. 4, the level of group success varied after 2 years of operation. The characteristic most strongly correlated with success in producing seed for sharing was the number of meetings that the group held during the cropping period, followed by group leader quality, the level of group trust and group management structure. Leadership quality was very closely related to the level of group trust and the number of meetings held during the season, leading to success in achieving seed production goals.

\subsubsection{Meeting frequency}

Holding group meetings allows knowledge to be shared and members to be updated on issues and progress regarding seed production. Meeting frequency was the most highly correlated factor affecting groups successfully reaching their objectives (Fig. 4), as found in other group studies (Das 2012; Anandajayasekeram et al.2008). Meetings also provide the environment for members to discuss their common problems and find solutions to them. A high meeting participation rate of members will also enhance group performance (Fischer and Quim 2011). During these meetings, it is possible for individuals to express and share knowledge, encourage a feeling of group ownership and improve group cohesiveness. Most groups $(60 \%)$ held four to six group meetings from land preparation through to seed storage. A further $34 \%$ of groups held one to three meetings over the same period. Six percent of groups met much more regularly. Leadership quality, the level of trust and the number of meetings that the groups held during the growing season were very closely correlated. All three of these characters led to higher shared seed production, as these governance characteristics play an essential role to enhance seed production performance in technology dissemination within rural communities (Khanal and Maharjan 2014).

\subsubsection{Management structure}

A clear management structure is crucial to effectively organize group activities. The group needed to have sufficient structure 
for the four positions (i.e. leader, secretary, treasurer and special coordinator) to be filled effectively. The results indicated that the surveyed groups possessed a range of group management components. Only seven percent of surveyed groups possessed a comprehensive group structure with all four positions filled. Nearly half of the 30 seed production groups did, however, have a group leader, secretary and treasurer; $26 \%$ of groups have a group leader and treasurer; $10 \%$ only a group leader; and $10 \%$ did not have a clear structure.

\subsubsection{Leadership quality, trust and decision-making}

Good leadership can lead to the success of a range of activities. Good leaders conferred with their group members regularly, thereby building a high level of trust. The survey results indicated that nearly half of the interviewed seed production groups stated that they have an excellent leader, $23 \%$ said they had a very good leader and $20 \%$ an average leader. Only one group was considered to possess poor leadership. It is believed that groups with highly intellectual leaders will contribute to a better performance in governance, hence improve seed diffusion (Khanal and Maharjan 2014). High-quality leaders managed to bring the members together to achieve the group's objectives and increased yields, the surplus of which could be distributed to family members and other farmers. This result corresponds with the findings of other authors such as Hansen et al. (2002) and Place et al. (2004). Effective decision-making processes within groups may lead to improved satisfaction of individuals within groups. An inclusive decision-making process involving all members contributed to improved group cohesion. This was particularly noticeable when the group leaders asked members' opinions before making decisions or when group members held a discussion and made a group decision. These consultative decision-making processes were evident in most of the surveyed groups and led to improved group performance. Sharing knowledge and helping each other occurred when everyone had an opportunity to participate in each decision-making process.

Nearly half of the 30 group members considered that an excellent level of trust existed within their group, whereas by contrast, $10 \%$ stated that trust among members was poor. This trust was developed through the members being fully informed of group activities and members being involved in decision-making. Successful groups also conducted their activities collectively rather than with individuals taking responsibility. This approach is common to agricultural groups established for large events such as land clearing, house construction and weeding.

\subsection{Support network}

Improved group cohesion resulted in individual team members receiving assistance outside of their seed production activities. For instance, in Ainaro, members helped each other to build houses, and in Liquiça, labour sharing improved. An additional benefit for the Liquiça groups was that, because they were recognized as well-functioning groups by the government, they became eligible to receive two-wheel tractors (single axle, self-powered tractor that can power a variety of farm implements). There was also more opportunity for group members to share resources. All 90 interviewed participants indicated that sharing seed was the main priority of being part of a seed production group. But, members also shared other resources. For example, most of the interviewees shared tarpaulins for seed drying, whereas others shared agricultural tools such as hoes, machetes and two-wheel tractors. The number of government extension visits to seed production groups during the cropping season ranged from 1 to 12 with an average of six. It is well documented that extension service delivery through farmer groups is cost-effective in developing countries (Khanal and Maharjan 2014). The suco (village) extension officers tended to visit during specific activities such as planting, weeding, harvesting, processing and seed selection and prior to seed storage. Forty-three percent of seed production groups received five to eight visits. Only one group stated that they were never visited by a village extension officer.

The correlation coefficient between the number of extension visits and seed production per member was low, implying that those groups with clear objectives may require fewer extension visits than others. Effective extension of new technologies to meet the needs of poor farmers is only possible if the rural extension officers are able to complement local knowledge (Pingali et al. 2006). This requires various participatory approaches and strategies to improve members' participation and cooperation, particularly if there is a high level of farmer individualism in the group (Sonam and Martwanna 2012).

Most surveyed farmers wanted to participate in group seed production activities to gain access to high-yielding variety and ensure their seed security. In addition, they considered that by being part of a group, they can share and learn from each other.

Non-group members often saw the benefits of being part of a seed production group and made enquiries about starting their own group. Non-group members were also aware of the extra assistance provided to group members by the village extension officers through training. Extension officers provided technical training to seed production groups on planting, weeding, seed selection methods and storage methods. This study hinted at farmers appreciating the extra technical skills and that these skills assisted improved seed production the second year. Being part of a group also facilitated an increase in support from non-governmental organizations. Extra support included receiving a two-wheel tractor, sprayers and other agricultural material. Apart from being able to use these facilities for group activities, individuals are able to access these 
resources for their own purposes and return them after completion. The awareness of these benefits by non-seed production group members led to the formation of 12 new groups. The new groups stated that they formed to gain easy access to high-yielding seed, reasonable assurance of seed security, to share group resources and to address individual problems that may be resolved by being part of a group.

In summary, the study showed that several characteristics were correlated with group effectiveness (as measured by the amount of seed distributed to each group member): meeting frequency $(r=0.69)$, leadership quality $(r=0.57)$, the level of group trust $(r=0.51)$ and group management structure $(r=$ 0.41 ). The success of a group in reaching its objectives was closely related to the strength of the group. Group strength is often determined by the degree of interaction and social relationship and social capital among members. A large majority of the seed production groups were either family and/or possessed the same goals and interests. The results closely echo the earlier finding of Jensen et al. (2014) that varietal adoption was strongly related to the closeness of the social relationships of the growers. Group members tended to be attracted to one another and have the strength, desire and commitment to remain a part of the group (Hansen et al. 2002; Dyaram and Kamalanabhan 2005; Klein and Mulvany 1995). The more successful interviewed groups were committed to long-term collaboration, and this can be developed further through positively aligning and linking technology dissemination with existing social capital. The potential of such linkages should be fully explored in technology dissemination within farming communities.

\section{Conclusion}

This study shows that for successful collective action to diffuse seed within communities by production groups, a group should have good governance including a clear management structure, a strong leader, a high degree of group trust and regular meetings. These traits all reflect the strength of social relationships and social capital of farmer groups. An important way to develop community groups in general and seed production groups in particular is to provide support to improve governance of already existing groups and to invest in the social preparation of new groups, so that they develop the social capital characteristics of successful groups. This is crucial for successful future technology diffusion in Timor-Leste, as well as in other developing countries.

Acknowledgments The authors wish to gratefully acknowledge the support of the Australian Government Department for Foreign Affairs and Trade (DFAT) and the Australian Centre for International Agricultural Research (ACIAR) to the Seeds of Life program. We would also like to thank the interviewed farmers who gave their time and resources to participate in the survey.

\section{References}

Anandajayasekeram P, Puskur R, Workneh S, Hoekstra D (2008) Concepts and practices in agricultural extension in developing countries. A source book, International Food Policy Research Institute (IFPRI), Washington, USA and International Livestock Research Institute (ILRI) Nairobi, Kenya

Bartham J, Chitemi C (2009) Collective action initiative to improve marketing performance: lessons from farmer groups in Tanzania. Food Policy 34:53-59. doi:10.1016/j.foodpol.2008.10.002

Das S (2012) Quality and performance of some selected self-help group in Assam. Asian J Res Bus Econ Man 2:21-27

Dyaram L, Kamalanabhan T (2005) Unearthed: the other side of group cohesiveness. J Soc Sci 10:185-190. doi:10.12691/jfe-1-4-3

Fischer E, Quim M (2011) Smallholder farmers collective action: what determines the intensity of participation? Proceedings of the German Development Economics Conference. Berlin 2011 no 28

Gianatti TM, Llewellyn RS (2003) Characteristics of successful farmerdriven Farming Systems groups in Western Australiahttp://www. grdc.com.au/uploads/documents/Characteristics $\% 20$ of $\%$ 20 successfu $1 \% 20$ farmer-driven $\% 20$ Farming $\% 20$ Systems $\%$ 20 Groups $\% 20$ in $\% 20$ Western $\% 20$ Australia.pdf. Accessed July 6, 2014

Hansen MH, Morrow JL, Batista JC (2002) The impact of trust on cooperative membership retention, performance, and satisfaction: an exploratory study. Int Food Agribus Manag Rev 5:41-59

Hay L (2005) Qualitative research methods in human geography, 2nd edn. Oxford University Press, Oxford

Jensen LP, Picozzi K, Monteiro ODC, Da Costa MDJ, Spyckerelle L, Erskine W (2014) Social relationships impact adoption of agricultural technologies: the case of food crop varieties in Timor-Leste. Food Sec 6:397-409. doi:10.1007/s12571-014-0345-5

Khanal NP, Maharjan KL (2014) Role of organizational governance in household level economic indicators: evidence from communitybased rice seed production of Nepal. J Int Dev Coop 20:13-28

Klein HJ, Mulvany PW (1995) Two investigations of the relationships among group goals, goal commitment, cohesion, and performance. Organ Behav Hum Decis Process 6:44-53

Lewis V, Mulvany PM (1997) A typology of community seed banks. Natural Resources Institute, University of Greenwich. NRI Project A0595

Lopes M, Nesbitt H (2012) Improving food security in Timor-Leste with higher yielding crop varieties. Australian Agricultural and Resource Economic Society, Mini Symposium, 8th-10th February 2012, Fremantle, Perth, Western Australia.

Markelova H, Meinzen-Dick R, Hellin J, Dohrn S (2009) Collective action for smallholder market access. Food Policy 34:1-7. doi:10. 1016/j.foodpol.2008.10.001

Pingali P, Stamulis K, Stringer R (2006) Eradicating poverty and hunger: towards a coherent policy agenda. Working Paper, Food and Agricultural Organisation of the United Nations (FAO), Rome 06:01

Place F, Kariuki G, Wangila J, Kristjanson P, Makauki A, Ndubi J (2004) Assessing the factors underlying differences in achievements of farmer groups: methodological issues and empirical findings from highlands of central Kenya. Agric Syst 82:257-272. doi:10.1016/j. agsy.2004.07.001

Sanginga PC, Lilja N, Tumwine J (2001) Assessing the quality of participation in Farmers' Research Groups on the Highlands of Kabale Uganda. CGIAR, Working document

Seeds of Life (2012a) Baseline survey. East Timorese Ministry of Agriculture and Fisheries (MAF), Dili, 83 pp

Seeds of Life (2012b) Annual research report 2012. East Timorese Ministry of Agriculture and Fisheries (MAF), Dili, 139 pp

Setimela PS, Monyo E, Banzinger M (2004) Successful Communitybased seed production strategies. CIMMYT, Mexico, $89 \mathrm{pp}$ 
Sonam T, Martwanna N (2012) Performance of smallholder dairy farmers' groups in the East and West central regions of Bhutan: members' perspective. J Agric Ext Rural Dev 4:23-29. doi:10.5897/JAERD11.106

Team S, Doss C (2011) The role of women in agriculture. Agricultural development economics division. Food and Agricultural Organisation of the United Nations, working paper 11:02

Thompson DWJ, Wallace JM, Jones PD, Kennedy JJ (2009) Identifying signatures of natural climate variability in time series of global-mean surface temperature: methodology and insights. J Clim 22:6120 6141. doi:10.1175/2009JCLI3089.1

Tiwari TP, Ferrara G, Urrea C, Katual RB, Koirala KB, Prasad RC, Gurung DB, Sharma D, Hamal B, Bhandari B, Thapa M (2009)
Rapid gain in yield and adoption of new maize varieties for complex hillside environments through farmers participation. II. Scaling-up the adoption through community-based seed production (CBSP). Field Crop Res 111:144-151. doi:10.1016/j.fcr. 2008.11.007

Vargas E, Burgoa W (2007) Farmers' participation in policy advocacy: reviewing two cases from Bolivia. http://www.future-agricultures. org/farmerfirst/files/T2c_Vargas.pdf. Accessed July 6, 2014

Williams R, Borges LF, Lacoste M, Andersen R, Nesbitt H, Johansen C (2012) On-farm evaluation of introduced maize varieties and their yield determining factors in East Timor. Field Crop Res 137:170 177. doi:10.1007/s12571-012-0228-6 